\title{
Supplemental Light-emitting Diode Effects on the Growth, Fruit Quality, and Yield of Two Greenhouse-grown Strawberry (Fragaria Xananassa) Cultivars
}

\author{
Andrea Stuemky and Mark E. Uchanski \\ Department of Horticulture and Landscape Architecture, Specialty Crops \\ Program, Colorado State University, Fort Collins, CO 80523
}

Additional index words. LED lighting, off-season strawberry production, food crop production

Abstract. Recent interest in off-season greenhouse-grown food crops, in combination with supplemental (top) lighting (SL), has created opportunities for local production of highvalue fruit crops such as strawberries (Fragaria $\times$ ananassa). Light-emitting diodes (LEDs) as SL can be tailored to a specific quality of radiation (i.e., wavelengths) to promote increased production and quality of greenhouse-grown crops. The objectives of this study were to evaluate the effects of three LED light bars on off-season controlled environmental agriculture (CEA) production of 2-day neutral strawberry cultivars: Albion and San Andreas. LED effects on overall vegetative biomass (e.g., stolon production, crown number, and leaf area), marketable fruit yield, and fruit quality [e.g., individual fruit weight and soluble solids content (SSC)] were measured during decreasing daylengths from Oct. to Dec. 2017 (Expt. 1) and increasing daylengths of Jan. to Apr. 2018 (Expt. 2). We hypothesized that the addition of SL via three LED treatments would increase measured parameters. Specifically, it was expected that the LED bars [high blue (HB) and low blue (LB)] with greater intensities of blue and red light would produce greater yields and also increase SSC of the berries. The hypotheses were tested by evaluating three LED light top bars [white far-red (WFR; 440-450 nm), HB, and LB], with wavelength peaks of blue $(450 \mathrm{~nm})$ and red $(665 \mathrm{~nm})$ light, but differing photosynthetic photon flux densities (PPFDs). Results from these experiments showed that individual strawberry fruit size and SSC were increased with the use of $\mathrm{HB}$ and LB LEDs during the shortening days of Expt. 1. Increased leaf area and crown number were also affected positively within all LED treatments (WFR, LB, HB) for 'San Andreas'. Relative to Expt. 1, the lengthening days of Expt. 2 elicited more limited fruit responses, although increased stolon production within all treatments was reported. In addition, differences between cultivars in leaf area and SSC were observed with 'San Andreas' growing larger leaves and 'Albion' berries having a greater SSC. Individual fruit weight of both cultivars responded similarly, with increased fruit size in $L B$ and HB, specifically within both Expt. 1 and Expt. 2. Our studies indicate that the addition of SL, in the form of $L B$ and HB improved overall strawberry fruit quality and plant growth during shortening daylengths and under greenhouse CEA conditions.

As a result of an increasing interest in local produce, the demand for fresh fruits and vegetables will likely increase and create opportunities for the produce industry to grow more food throughout the entire year. Already-lucrative fruit crops, such as berries,

Received for publication 8 Apr. 2019. Accepted for publication 11 July 2019.

Published online 10 December 2019

We express our gratitude to the Department of Horticulture \& Landscape Architecture, the Agricultural Experiment Station, and the Statistical Laboratory at Colorado State University, Fort Collins, $\mathrm{CO}$

A.S. is the corresponding author. E-mail: andrea. stuemky@colostate.edu.

This is an open access article distributed under the CC BY-NC-ND license (https://creativecommons.org/ licenses/by-nc-nd/4.0/). are even more highly valued when consumers can purchase produce from a local grower or market (Conner et al., 2009). California, Florida, Oregon, and Washington present the largest amount of strawberry (Fragaria $\times$ ananassa) production in the United States, accounting for $96 \%$ of the land area $(20,437 \mathrm{ha})$, with California and Florida alone making up roughly 92\% (National Agricultural Statistics Service, 2017). For the population of U.S. citizens that does not live in those few states, finding highquality, local produce can prove to be challenging, especially during the winter.

The use of heated greenhouse structures, coupled with SL, may be helpful in filling the evident demand for fresh, local produce during the coldest months of the year. Producing an edible horticulture crop using this combination of factors is called controlled environmental agriculture, or CEA (Bradford et al., 2010; Hamano et al., 2016). Although moving production of high-value crops indoors, whether greenhouse or warehouse growing, presents its own challenges (e.g., structural and electrical costs, insect and disease pressures, supplying nutrients), it also allows growers more control over climate variables and can help to close the gap of seasonally unavailable produce for local consumers.

When growing in greenhouses, extra lighting is usually necessary to supplement natural sunlight, which is typically less intense in the winter than in the summer months. Day lengths are also shorter during the cooler winter months. Traditionally, high-intensity discharge forms of SL (e.g., high-pressure sodium) have been used in greenhouses to allow for winter production, but LEDs have quickly become an alternative that growers are adopting (Park et al., 2014; Singh et al., 2015). LEDs typically produce less heat and are energy efficient, and wavelengths can be adjusted for each individual crop's growing requirements. LEDs present greenhouse growers with ways to explore expanded production and sustainability, as well as opportunities for off-season production (Massa et al., 2008; Morrow, 2008). Individual diodes that make up LED light fixtures range in their color spectra (i.e., wavelengths), which are typically comprised of a combination of blue, red, far-red, and/or white. Specifically, the combination of red/ blue and red/blue/white LEDs has been shown to increase overall photosynthetic pigments as well as the net photosynthetic rate in cherry tomatoes (Liu et al., 2011), and increased leaf area (Son et al., 2018). Solesource (SS), single-wavelength blue LEDs $(475 \mathrm{~nm})$ have also been reported to increase individual strawberry size by two times on average when compared with SS, singlewavelength red LEDs alone (Magar et al., 2018).

Many cultivars of strawberry only flower and bear fruit during specific times of the year as a result of corresponding daylength. This phenomenon is referred to as the photoperiod response. However, certain strawberry cultivars produce flowers and fruit independent of daylength. Day-neutral strawberry cultivars, unlike June-bearing (i.e., short-day) cultivars, produce continuously if conditions are conducive to growth. In addition to being day neutral, these cultivars are also remontant (i.e., blooming or producing a crop more than

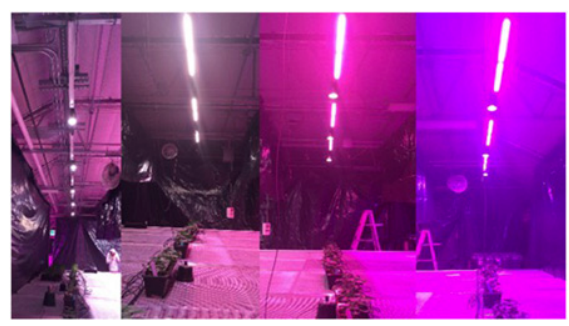

Fig. 1. Light-emitting diode lighting treatments at night. (Left to Right) Control with flowering bulbs, whit/far-red, low blue with flowering bulbs, and high blue with flowering bulbs. 


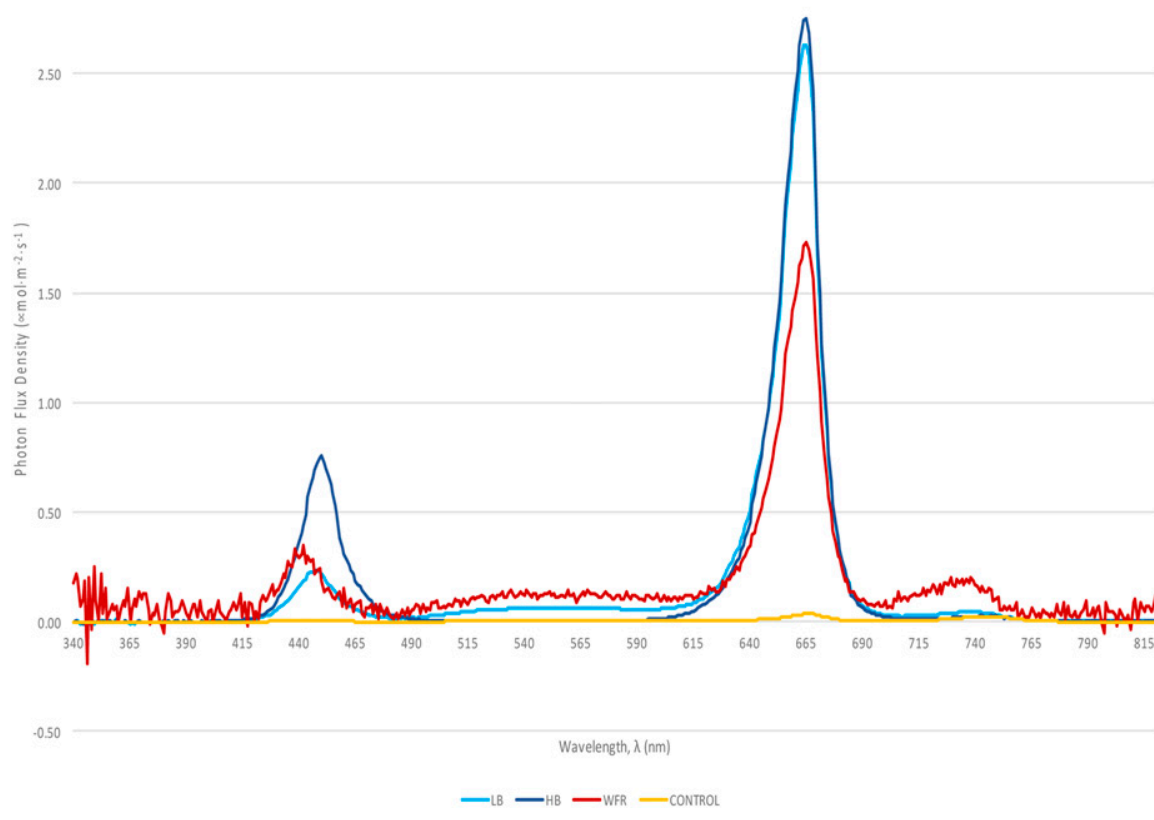

Fig. 2. Photosynthetic photon flux density of individual light-emitting diode top lights in an isolated environment (i.e., individually separated treatments at night).

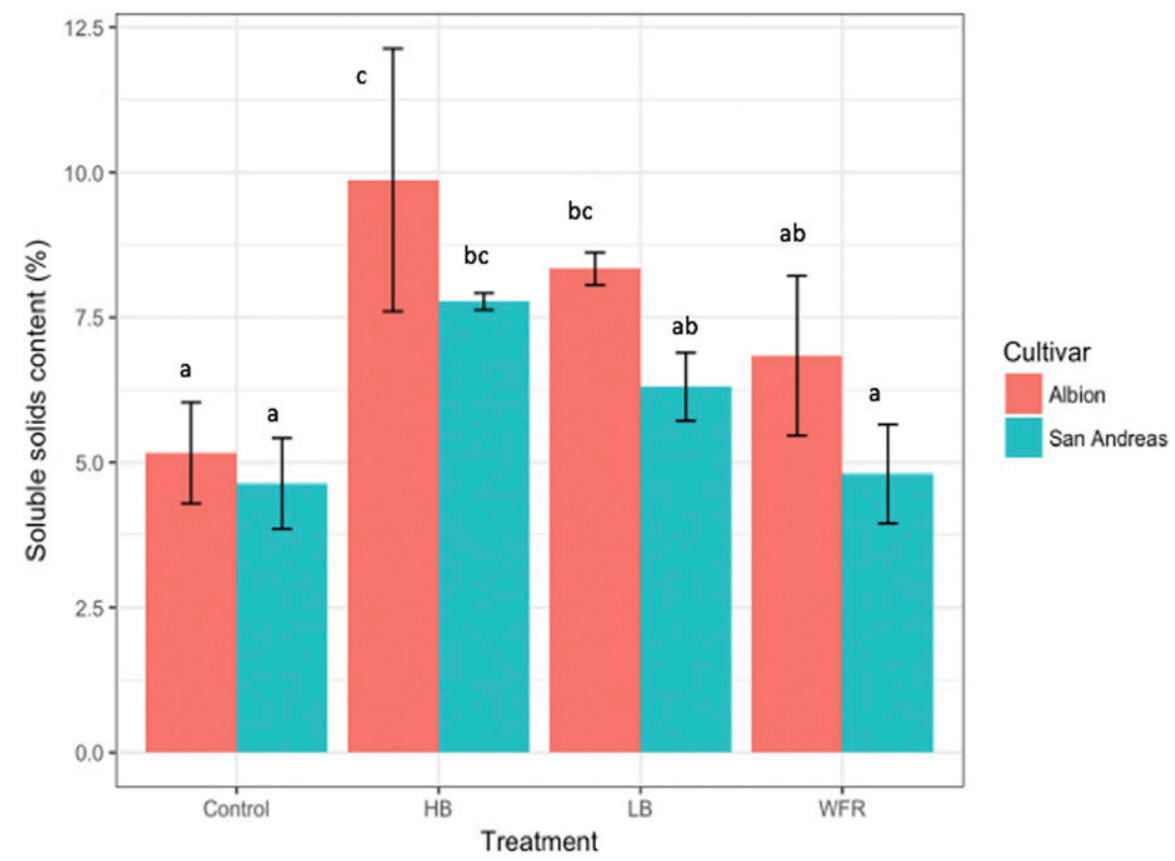

Fig. 3. Analysis of mean soluble solids content of strawberry cultivars Albion and San Andreas in response to treatments (control; HB, high blue; LB, low blue; and WFR, white/far-red) in Expt. 1 (Oct. 2017 Dec. 2017) in Fort Collins, CO. SE bars indicate the mean \pm SE $(n=3)$. Different lowercase letters symbolize statistically significant differences between treatments and cultivars.

once in a given season). This is a highly desirable trait for growers because it ensures continuous harvests throughout the entire crop growth cycle. CEA strawberry production with supplemental lighting, coupled with optimum daytime growing temperatures $(20$ to $24{ }^{\circ} \mathrm{C}$ ) (Kimura, 2008), has been shown to increase flower production in day-neutral strawberry cultivars (Nishiyama and Kanahama, 2000). It has also been demonstrated well documented (Hemming, 2011). Access to this information could present a large advantage to current and future strawberry producers, particularly with the increasing amounts of greenhouse and warehouse (i.e., SS lighting) growing that has been seen during the past few years (Cherney, 2018). Commercially available fixtures currently on the market include different ratios and wavelengths of diodes that may have impacts on strawberry growth, fruit quality, and yield.

The objective of our study was to evaluate the efficacy of three commercially available LED SL top light bars with different blue, red, and far-red wavelengths at differing $P P F D$ s for strawberry production in a greenhouse during two off-season periods (October-December and January-March) in northern Colorado. Furthermore, we evaluated two day-neutral cultivars of strawberries under these conditions. Crop parameters measured included overall berry quality, soluble solids content $\left({ }^{\circ} \mathrm{Bx}\right)$, a U.S. Department of Agriculture (USDA) strawberry fruit grade rating, fruit marketability, total yield, individual fruit size, fruit number, crown number, vegetative biomass, and stolon production. We hypothesized that with the addition of LED $\mathrm{SL}$, an increase in all measured parameters would be observed. It was also hypothesized that LED light bars with greater intensities of blue and red wavelengths would increase yield and SSC of the fruit. Last, we expected the two day-neutral strawberry cultivars to respond similarly to the three supplemental LED lighting treatments.

\section{Materials and Methods}

Off-season greenhouse strawberry trials were conducted at Colorado State University Horticulture Center greenhouses (Fort Collins, CO; lat. $40^{\circ} 33^{\prime} 54.8^{\prime \prime} \mathrm{N}$, long. $105^{\circ} 05^{\prime} 06.2^{\prime \prime} \mathrm{W}$; elevation, $1525 \mathrm{~m}$ ) during two off-season production periods to investigate the effects of LED top lights on the growth, yield, and fruit quality of two day-neutral strawberry cultivars. The first period (Expt. 1) consisted of naturally shortening days [Oct.-Dec. 2017, 11 h 45 min on 1 Oct. 2017 down to $9 \mathrm{~h} 17 \mathrm{~min}$ on $15 \mathrm{Dec}$. 2017, with an average of $10 \mathrm{~h} 31 \mathrm{~min}$ daylight for that time period (National Weather Service, 2019)]. The second period (Expt. 2) consisted of naturally lengthening days [Jan.-April 2018, $10 \mathrm{~h}$ 36 min on 15 Jan. 2018 up to $13 \mathrm{~h} 18 \mathrm{~min}$ on 15 Apr. 2018, with an average of $11 \mathrm{~h}$ 56 min for that time period (National Weather Service, 2019)].

\section{Plant material}

Strawberry (Fragaria ×ananassa Duch. 'Albion' and 'San Andreas') plugs were received from a commercial grower (McNitt's Growers, Carbondale, IL) on 21 Sept. 2017 and were used for Expt. 1. Plugs consisted of stolon cuttings rooted in a soilless media. Plugs were transplanted into bato buckets $(99 \times 17.7 \times 18.5 \mathrm{~cm}, 6.22-\mathrm{L}$ volume; Meter Trough, AMA Plastics, Kingsville, Ontario, Canada), and extras were planted into $8.9-\mathrm{cm}$ 


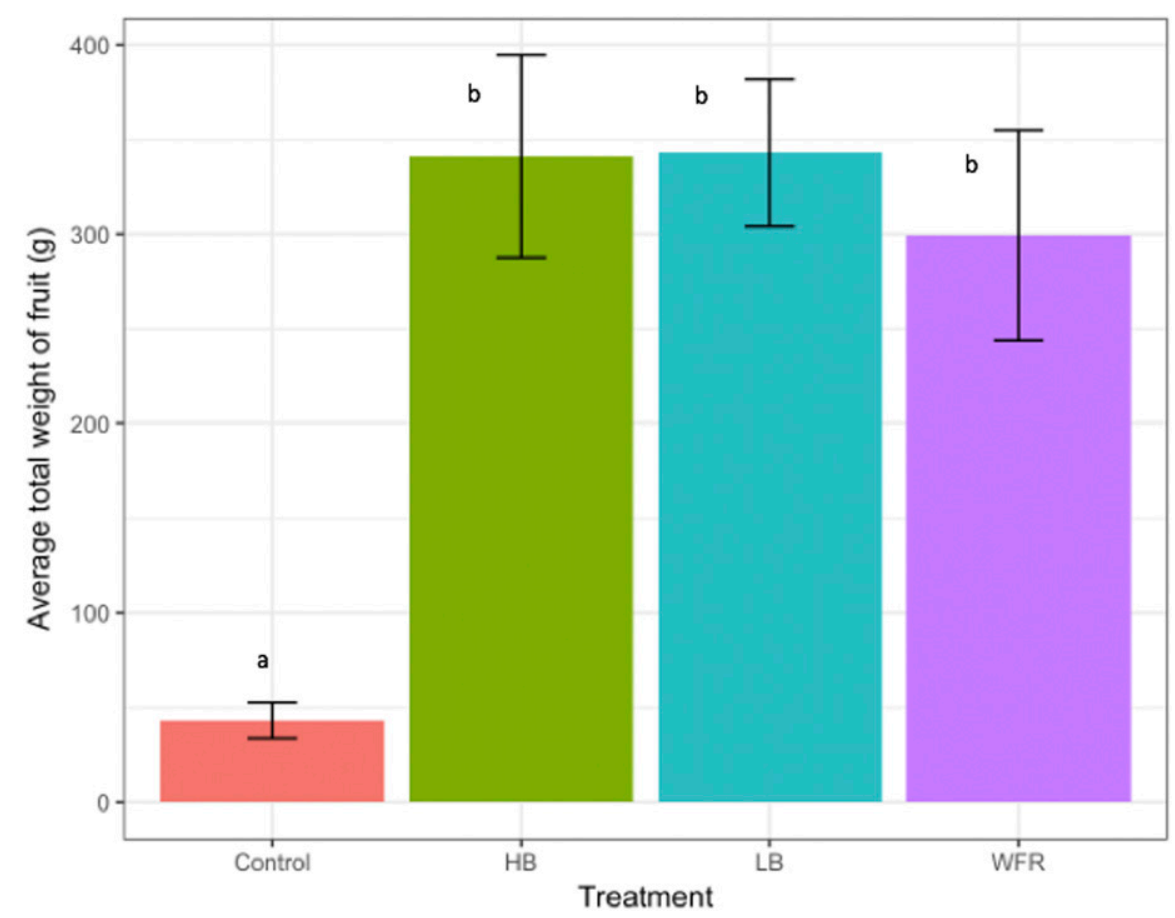

Fig. 4. Analysis of mean total weight of all marketable fruit of both cultivars - Albion and San Andreascombined, in response to treatments (control; HB, high blue; LB, low blue; and WFR, white/far-red) in Expt. 1 (Oct. 2017-Dec. 2017) in Fort Collins, CO. SE bars indicate the mean $\pm \mathrm{SE}(\mathrm{n}=6)$. Averages for all treatments are displayed because the cultivar main effect was not significant. Different lowercase letters symbolize statistically significant differences between treatments.

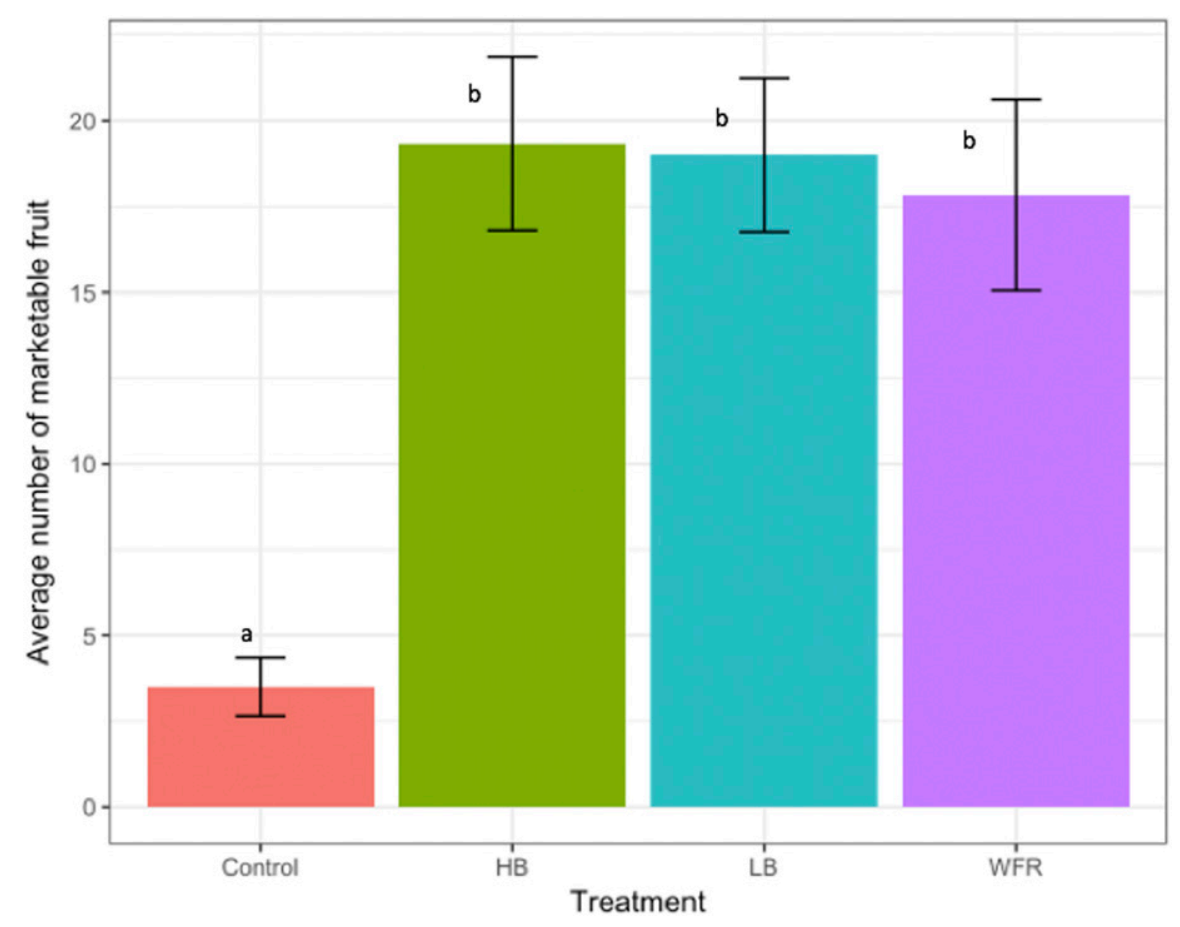

Fig. 5. Analysis of the mean number of all marketable fruit of both cultivars - Albion and San Andreascombined, in response to treatments (control; HB, high blue; LB, low blue; and WFR, white/far-red) in Expt. 1 (Oct. 2017-Dec. 2017) in Fort Collins, CO. SE bars indicate the mean $\pm \mathrm{SE}(\mathrm{n}=6)$. Averages for all treatments are displayed because the cultivar main effect was not significant. Different lowercase letters symbolize statistically significant differences between treatments.

(3.5-inch) pots for future use. Each bato bucket was considered an experimental unit and was planted with six plants, $15 \mathrm{~cm}$ apart, in a coco-coir and peat-based growing sub- strate (BVB BC5 Strawberry Mix, AMA Plastics). Three batos of both cultivars, Albion and San Andreas, were assigned randomly to each of the four LED light treatments and arranged in a randomized complete block design (north-south) across three rolling benches (replications). Plants were irrigated using individual drip lines and $1.98 \mathrm{~L}(0.5 \mathrm{gal}) / \mathrm{h}$ emitters, with 90 to 125 $\mathrm{mL} \cdot \mathrm{d}^{-1}$, depending on watering needs. Electrical conductivity (EC) and $\mathrm{pH}$ of influx were measured twice a month using a digital $\mathrm{EC}$ and $\mathrm{pH}$ meter (MC110 $\mathrm{pH}$ Monitor, Milwaukee Instruments, Inc., Rocky Mount, NC; MC310 EC Monitor, Milwaukee Instruments, Inc.) to ensure a range of 0.9 to $1.2 \mathrm{mS} \cdot \mathrm{cm}^{-2}$ and 5.5 to 6.5 , respectively. Plants were fertigated with a water-soluble nutrient concentrate containing $8 \% \mathrm{~N}, 12 \%$ $\mathrm{P}, 32 \% \mathrm{~K}, 0.5 \% \mathrm{Mg}$, and $0.25 \% \mathrm{~S}$ (HydroGardens Strawberry Formula, CO Springs, $\mathrm{CO})$, and $\mathrm{Ca}\left(\mathrm{NO}_{3}\right)_{2}\left(0.95 \mathrm{~g} \cdot \mathrm{L}^{-1}\right.$ for $100 \mathrm{x}$ concentrate). Average greenhouse temperatures were set to daytime temperatures of $20{ }^{\circ} \mathrm{C}$ and $15{ }^{\circ} \mathrm{C}$ at night, with a range of relative humidity of $40 \%$ to $60 \%$.

Flowers were hand-pollinated using a small, short-bristled brush at anthesis to supplement pollination that likely occurred within the greenhouse resulting from ventilation and fan airflow.

For Expt. 2, extra plugs from the first experiment were placed into a commercial cooler at $4.4^{\circ} \mathrm{C}\left(40^{\circ} \mathrm{F}\right)$ from Oct. 2017 to Jan. 2018. Plants were then transferred from the cooler and allowed to acclimate under greenhouse conditions for $7 \mathrm{~d}$ before being transplanted into bato buckets (Meter Trough, AMA Plastics). Once acclimated plugs were planted, they were rerandomized and irrigated using the same protocols as Expt. 1.

Common greenhouse pests included twospotted spider mite, thrips, aphids, and a fungal disease, powdery mildew. Insects and powdery mildew were managed using biological controls [Swirskii-System (Amblyseius swirskii), Californicus-System (Amblyseius fallacis), BioBest, Leamington, Ontario, Canada] and potassium bicarbonate (sprayed weekly), respectively.

\section{SL treatments}

A different LED top light bar was applied to each treatment row (LED light bars were not used in the control) (Expts. 1 and 2) and ran continuously for $16 \mathrm{~h} \cdot \mathrm{d}^{-1}(0300-1700 \mathrm{HR})$ in addition to natural sunlight. LED light bars were measured individually in isolation (i.e., within greenhouse at night) at $2.13 \mathrm{~m}$ away, using a spectroradiometer (SS-110; Apogee Instruments, Inc., Logan, UT) to determine wavelength peaks of blue and red diodes. A total greenhouse (natural + artificial irradiance) $P P F D$ of $90 \mu \mathrm{mol} \cdot \mathrm{m}^{-2} \cdot \mathrm{s}^{-1}$ was measured and the daily light integral (DLI) of 7 to $10 \mathrm{~mol} \cdot \mathrm{m}^{-2} \cdot \mathrm{s}^{-1}$ was calculated at plant height using a quantum sensor (LI190R; LI-COR, Inc., Lincoln, NE). Each LED treatment was positioned above the plants from north to south across the top of a set of rolling benches (running east to west) and was separated by $6-\mathrm{mm}$ black plastic curtains (height, $1.5 \mathrm{~m}$ ) to create individually lighted areas (Fig. 1). Depending on the treatment, the light fixtures were placed at 


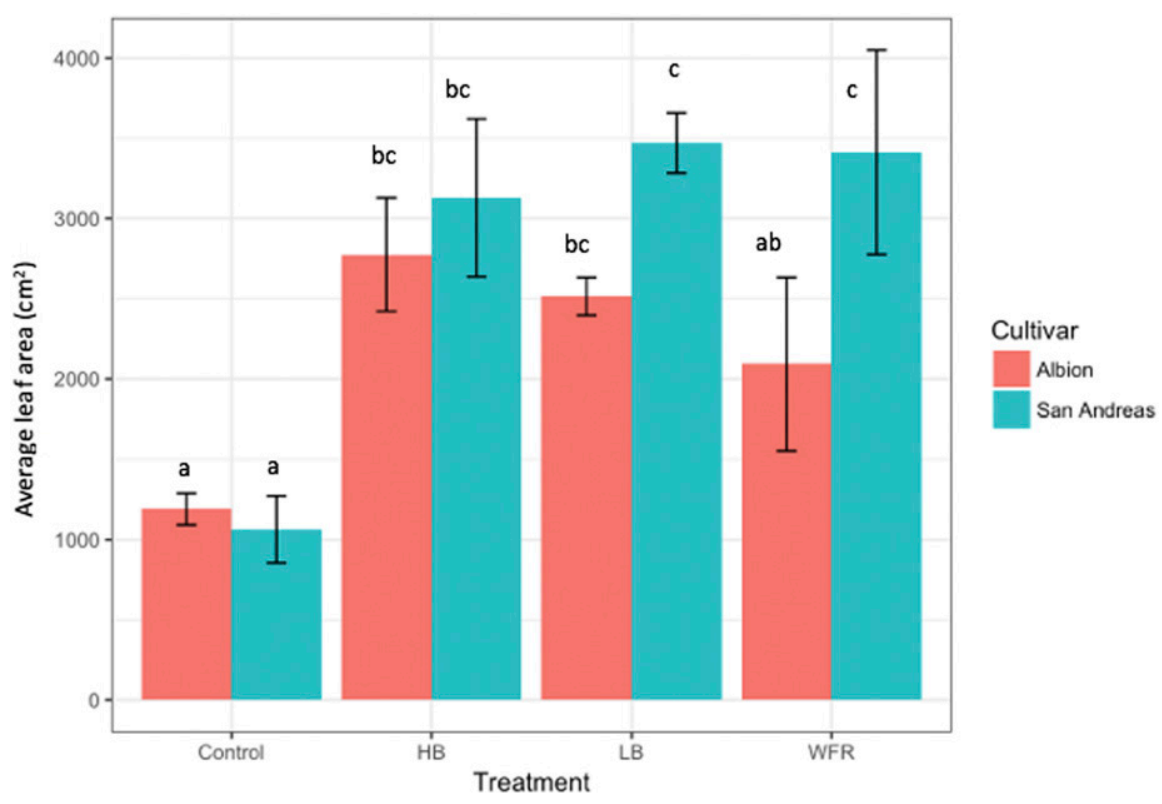

Fig. 6. Analysis of mean leaf area of the inner four plants (within a replication/bato) of cultivars Albion and San Andreas in response to treatments (control; HB, high blue; LB, low blue; and WFR, white/far-red) in Expt. 1 (Oct. 2017-Dec. 2017) in Fort Collins, CO. SE bars indicate the mean \pm SE $(n=3)$. Different lowercase letters symbolize statistically significant differences between cultivars and treatments.

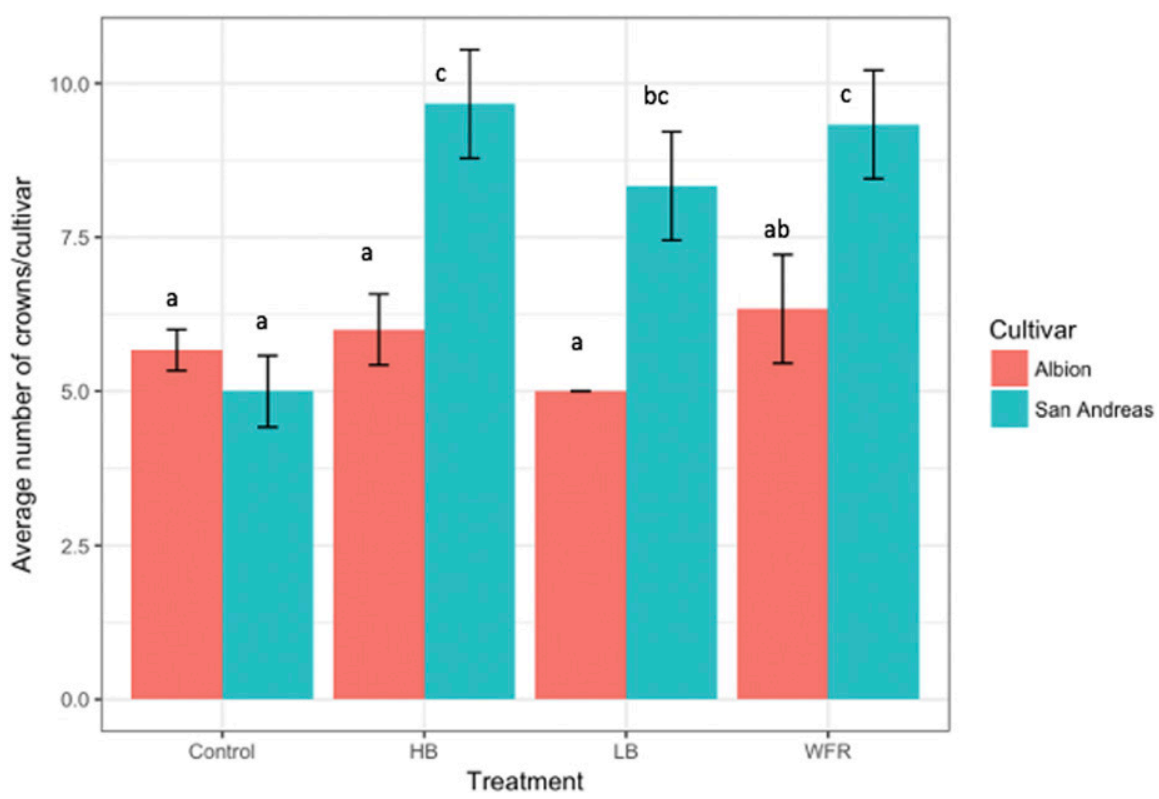

Fig. 7. Analysis of the mean number of strawberry crowns/replication of cultivars Albion and San Andreas in response to treatments (control; HB, high blue; LB, low blue; and WFR, white/far-red) in Expt. 1 (Oct. 2017-Dec. 2017) in Fort Collins, CO. SE bars indicate the mean \pm SE $(n=3)$. A significant interaction between cultivar and treatment effects was noted. Different lowercase letters symbolize statistically significant differences between cultivars and treatments.

varying heights to ensure a constant PPFD $\left(90 \mu \mathrm{mol} \cdot \mathrm{m}^{-2} \cdot \mathrm{s}^{-1}\right)$ and DLI were obtained in each lighted row at the start of each experiment. For Expt. 2, lighted treatments were rerandomized within the same greenhouse bay and benches.

LED light treatments (Fig. 1) were composed of commercial fixtures and defined by the manufacturer's labels as

- Control = flowering bulbs alone (deep red/ white/far-red), $11 \mathrm{~W}$ mental unit, macerated, and homogenized. Juice was separated from the fruit solids with cheese cloth to obtain a liquid sample and was placed onto a digital refractometer (Reichert AR200; Fisher Scientific, Hampton, $\mathrm{NH}$ ), that was calibrated with distilled water. Measurements were taken at room temperature using the Brix-TC (temperature compensated) setting and were recorded for each experimental unit. Strawberry fruit were weighed individually and assigned a USDA grade individually throughout the growing season to quantify overall reproductive yield and marketable yield (U.S. Department of Agriculture, 2006).

Leaf area, crown number, and stolon measurements. After the final fruit harvest, plants were cut to the base of the crown and fruit pedicels, leaves (petioles included), and stolons were separated and weighed for each experimental unit. Leaves were scanned with a leaf area meter (LI-3100C Area Meter; LICOR, Inc.) and were placed back with the petioles into individual paper bags. Plant material was placed in an oven at $70{ }^{\circ} \mathrm{C}$ for $48 \mathrm{~h}$, then was weighed to determine dry biomass. The number of crowns in each experimental unit was counted at the beginning and end of the experiments to characterize overall vegetative growth of the plants.

\section{Statistical analysis}

Data were analyzed as a randomized complete block design using a factorial analysis of variance (ANOVA) carried out in RStudio platform (version 3.3.1; R Studio, Boston, MA). A linear model [Model $=\operatorname{lm}$ (Response $\sim$ Block + Treatment $\times$ Cultivar, data) $(y=\mu+B+T+C+T \times C)]$ using the lsmeans package was used and significance was reported at $\alpha=0.05$. Data were assessed using the Shapiro-Wilk test for assumptions of normality $(\alpha=0.05)$. Lowercase letters in figures symbolize statistically significant differences between treatments. Main effects of treatment and main effects of cultivar are shown when data analyses are significant and did not reveal an interaction. Block effects are reported when significant. Expt. 1 and Expt. 2 were analyzed separately, except for individual strawberry fruit weight, which was combined because of similarities in the data.

\section{Results}

\section{PPFD of individual LED top light bars}

Spectroradiometer readings at bench height $(2.13 \mathrm{~m})$ showed measurements of the LB and HB LED lighting treatments at 455-nm (blue) and 665-nm (red) light peaks (Fig. 2). The WFR LED lighting treatment had a measured blue peak at $440 \mathrm{~nm}$, a red peak at $665 \mathrm{~nm}$, and a far-red peak at $735 \mathrm{~nm}$. The highest red and blue photon count was measured in the HB LED treatment at 0.75 $\mu \mathrm{mol} \cdot \mathrm{m}^{-2} \cdot \mathrm{s}^{-1}$ at $455 \mathrm{~nm}$ and $2.75 \mu \mathrm{mol} \cdot \mathrm{m}^{-2} \cdot \mathrm{s}^{-1}$ at $665 \mathrm{~nm}$. The PPFD of the LB LED treatment measured $0.25 \mu \mathrm{mol} \cdot \mathrm{m}^{-2} \cdot \mathrm{s}^{-1}$ at $445 \mathrm{~nm}$ and $2.60 \mu \mathrm{mol} \cdot \mathrm{m}^{-2} \cdot \mathrm{s}^{-1} 665 \mathrm{~nm}$; and the WFR LED treatment at $0.35 \mu \mathrm{mol} \cdot \mathrm{m}^{-2} \cdot \mathrm{s}^{-1}$ at $445 \mathrm{~nm}, 1.75 \mu \mathrm{mol} \cdot \mathrm{m}^{-2} \cdot \mathrm{s}^{-1}$ at $665 \mathrm{~nm}$, and 


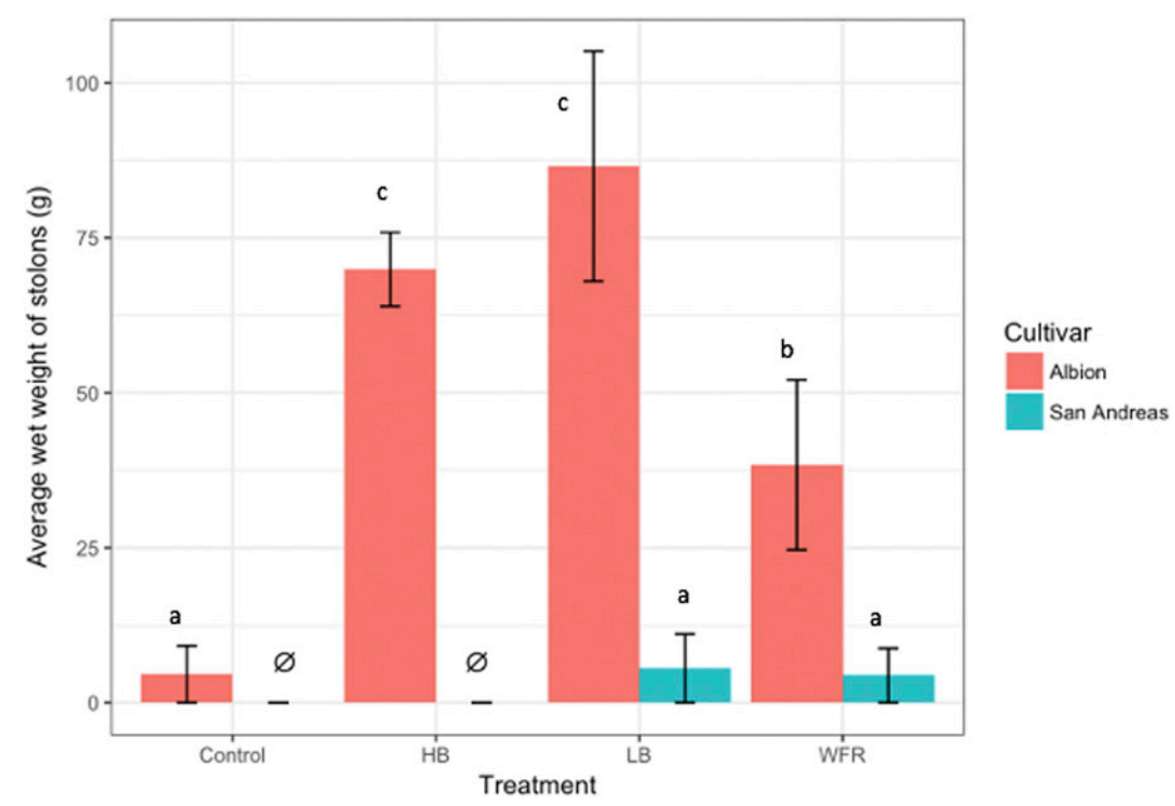

Fig. 8. Analysis of the mean stolon weight of cultivars Albion and San Andreas in response to treatments (control; HB, high blue; LB, low blue; and WFR, white/far-red) in Expt. 1 (Oct. 2017-Dec. 2017) in Fort Collins, CO. SE bars indicate the mean \pm SE $(n=3)$. Averages for both cultivars and all treatments are displayed, although a significant interaction between cultivar and treatment effects was noted. Different lowercase letters symbolize statistically significant differences between cultivars and treatments. Note: 'San Andreas' replications in the control and HB light-emitting diode treatments produced no stolons (i.e., $0 \mathrm{~g}$ stolons).

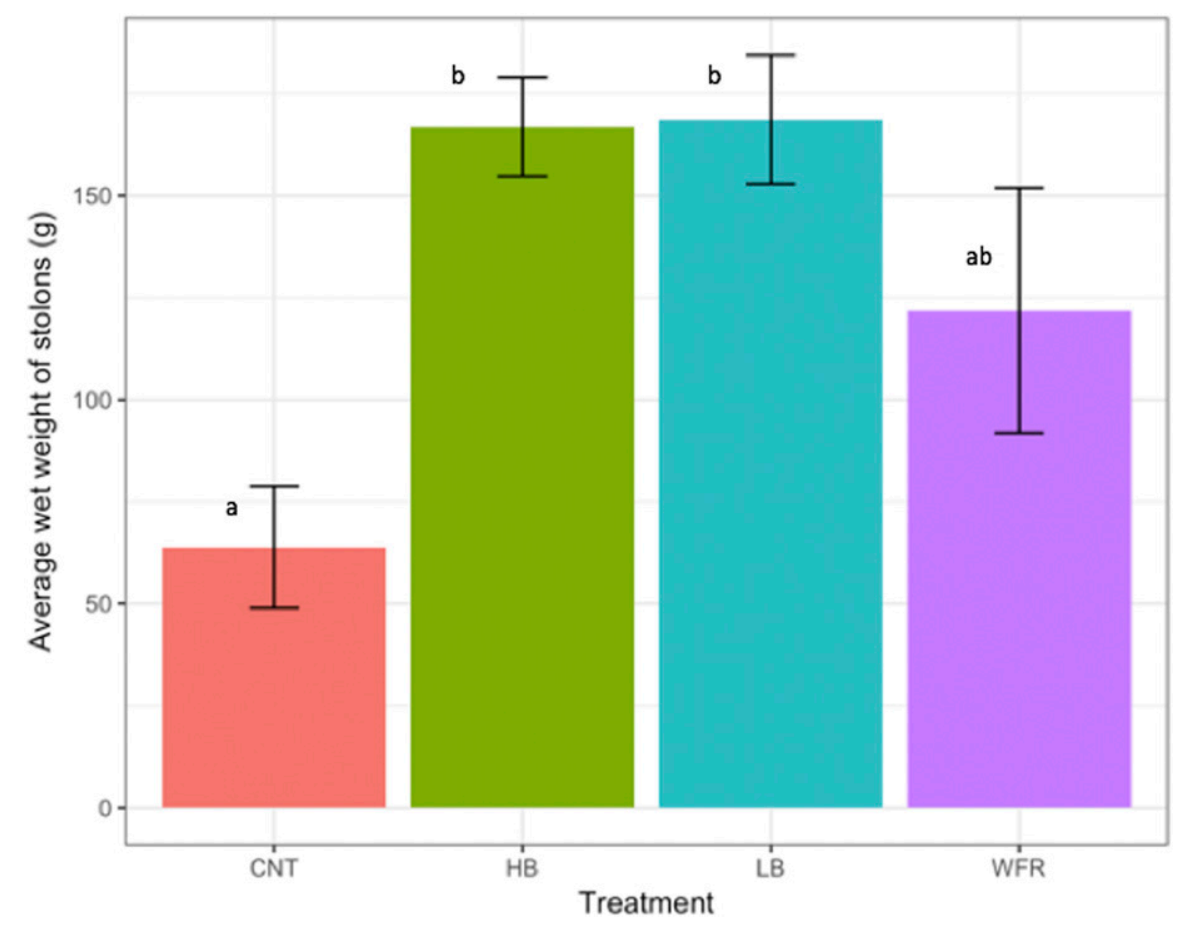

Fig. 9. Analysis of the mean stolon weight of both cultivars-Albion and San Andreas-combined, in response to treatments (CNT, control; HB, high blue; LB, low blue; and WFR, white/far-red) in Expt. 2 (Jan. 2018-April 2018) in Fort Collins, CO. SE bars indicate the mean $\pm \mathrm{SE}(\mathrm{n}=6)$. Averages for all treatments are displayed because the cultivar main effect was not significant. Different lowercase letters symbolize statistically significant differences between treatments.

$0.20 \mu \mathrm{mol} \cdot \mathrm{m}^{-2} \cdot \mathrm{s}^{-1} 735 \mathrm{~nm}$. This information is not typically provided by manufacturers.

Expt. 1 (Oct.-Dec. 2017). There was a significant main effect of both cultivar and treatment for SSC, but no interaction. SSC for
'Albion' berries in LB and HB, and 'San Andreas' berries in HB increased in size compared with the control (Fig. 3). The average total yield (measured in grams) of all marketable strawberry fruit for each treat- ment (HB, LB, and WFR) was statically greater than the control (Fig. 4). The average number of marketable fruit was statistically similar and greater than the control in all lighted treatments for both cultivars (Fig. 5). Cultivars were combined because an ANOVA revealed there was a main effect of treatment, but not cultivar, with no interaction. A significant blocking effect was noted.

There was a significant main effect for both treatment and cultivar, with no interaction. Leaf area of 'San Andreas' plants in all of the lighted treatments (WFR, LB, and HB) were significantly greater than the leaf area of the control. Leaf area of the 'Albion' plants in the HB and LB LED treatments were also significantly greater than the control (Fig. 6). Both cultivars in Expt. 1 responded to the lighting treatments by increasing leaf area, with the greatest area in the LB and HB light treatments.

There was a significant interaction between cultivars and treatments, and significant main effects of both cultivar and treatment for crown number measurements. The average number of 'San Andreas' strawberry crowns was statistically greater than the control in the HB, LB, and WFR LED treatments. Average numbers of 'Albion' crowns were significantly greater only in the WFR treatment (Fig. 7).

A significant main effect of treatment and cultivar, as well as an interaction, was revealed in vegetative stolon production measurements using ANOVA. An increase in stolon production was seen in 'Albion' strawberry plants for each lighting treatment compared with the control, whereas 'San Andreas' strawberry plants showed very little runner production overall (Fig. 8).

Expt. 2 (Jan.-Apr. 2018). A significant main effect of cultivar, but not treatment, allowed for treatments to be combined for SSC in Expt. 2. 'Albion' berries had significantly greater percentages than 'San Andreas'. Results not shown.

Treatments were also combined for average leaf area measurements because 'San Andreas' plants had significantly larger leaves than 'Albion' plants $\left(4321 \mathrm{~cm}^{2}\right.$ vs. $2855 \mathrm{~cm}^{2}$, respectively). There was no significant difference in leaf area between LED lighting treatments. Results not shown.

Both cultivars responded similarly to naturally lengthening days in Expt. 2 with increased runner production in all lighted treatments (Fig. 9). Cultivars were combined because there was no significant difference between 'Albion' and 'San Andreas'. The LB and HB treatments produced an average weight of $2.6 \times$ more stolon vegetation than the control (168 and $166 \mathrm{~g}$ vs. $63 \mathrm{~g}$, respectively).

There were no significant differences measured between cultivars or LED treatments for overall marketable yield, marketable fruit number, or crown number during the lengthening days of Expt. 2.

\section{Combined Expts. 1 and 2: Individual strawberry fruit yield/weight measurements.}

Data from Expt. 1 and Expt. 2 were combined because of similar treatment responses. There was a significant main effect for both cultivar and treatment, but no 


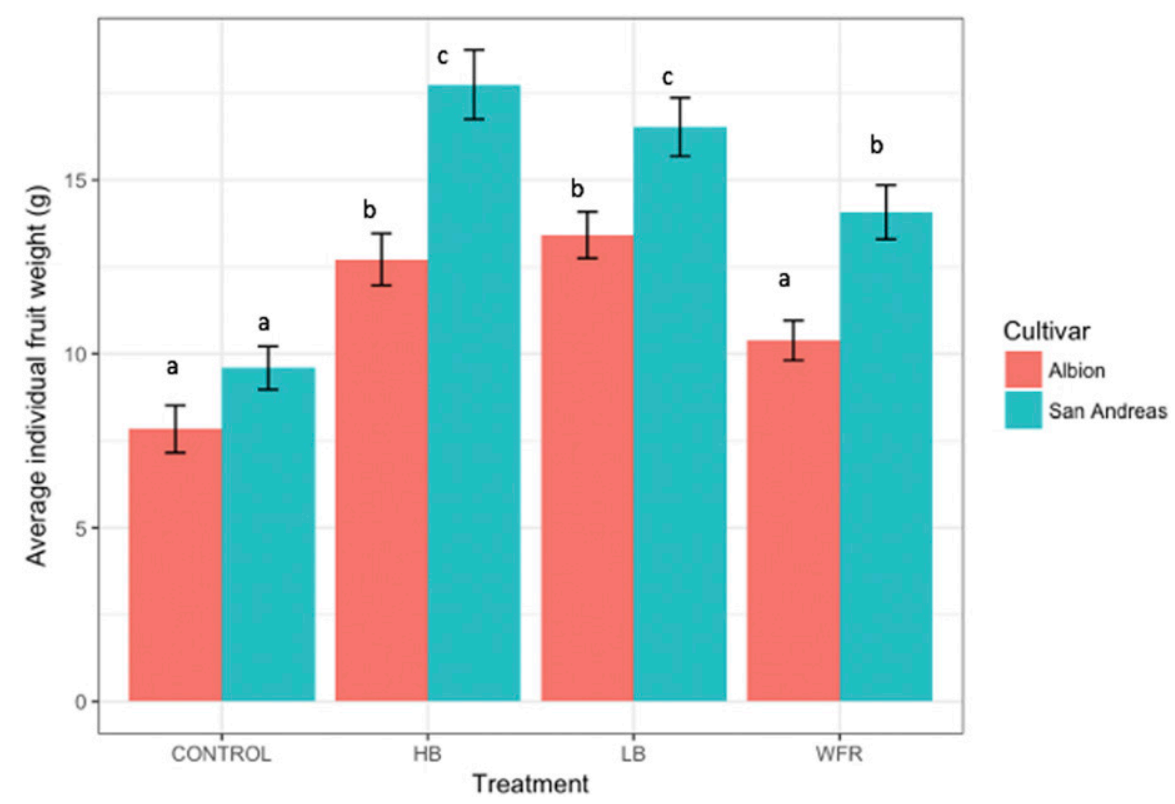

Fig. 10. Mean individual strawberry fruit weight of 'Albion' and 'San Andreas' in response to lightemitting diode treatments (control; HB, high blue; LB, low blue; and WFR, white/far-red) in Fort Collins, CO. Data were combined for Expt. 1 and Expt. 2 (Oct. 2017-Dec. 2017, Jan. 2018-April 2018). SE bars indicate the mean \pm SE. Different lowercase letters symbolize statistically significant differences between cultivars.

interaction in both experiments. Individual 'San Andreas' berries in the lighted treatment groups were significantly larger than the control, but not from each other. 'Albion' berries in treatment groups HB and LB were similar in weight and larger than the WFR and control group (Fig. 10). A significant blocking effect was noted.

\section{Discussion}

Supplemental lighting is a key factor that can allow growers to produce off-season food crops despite naturally short days (Dorais, 2003). In our study, however, there appeared to be a different response to the shortening days of Expt. 1 compared with the lengthening days of Expt. 2 for most factors measured. Specifically, total yield and SSC were improved with the use of HB and LB LEDs during shortening days of Expt. 1. In addition, individual fruit weight increased in the $\mathrm{HB}$ and LB LED treatments in both experiments. Other studies have reported similar findings of increased weight of reproductive structures (flowers and fruits) when using SS blue (470-nm) LED lighting in a greenhouse environment (Magar et al., 2018). Increased fruit yield was also reported by Choi et al. (2015), in which the greatest yields were harvested under greenhouse conditions with SL treatments of blue (448-nm) LED lighting and a combination of blue $(448 \mathrm{~nm})$ and red (634 and $665 \mathrm{~nm}$ ) at a 3:7 ratio, compared with red SL LED (634- and 665-nm) lighting alone. Yoshida et al. (2016) described accelerated harvests resulting from earlier flowering under blue light environments during the nursery period of production. However, there were no detectable differences in between separate SS red and SS blue LED growth chamber treatments. However, Nadalini et al. (2017) did find that the average fruit weight (measured in grams) and fruit set (measured as a percentage) was significantly greater under the blue LED light treatment. Similarly, a greenhouse study on frigo (plants harvested when dormant outdoors and kept in cold storage until needed) strawberries also reported increased fruit size in LED treatments of red + blue light compared with red LED light alone (Samuolienè et al., 2010).

Leaf area and crown number were affected positively by all LED treatments (WFR, LB, and HB) in 'San Andreas' plants during the shortening days of the winter months (October-December). It appeared that the SL provided during a typically light-limited time of year allowed for strawberry plants to increase both reproductive and vegetative growth, but to a lesser extent during the lengthening days of spring (January-April). However, other studies have documented that SS red lighting increased specific leaf (the ratio of leaf area and dry weight of leaves, measured in square meters per kilogram) when compared with SS blue lighting, whereas SS blue lighting increased over all crown weight (Nadalini et al., 2017). Wu et al. (2011) reported similar findings in a growth chamber: Combined SS lighting of $70 \%$ red LED light and $30 \%$ blue LED light increased overall crown diameter when compared with traditional T5 fluorescent lighting.

The lengthening days of Expt. 2 elicited limited responses, although stolon production increased in all treatments, as well as differences between cultivars in leaf area and SSC. Stolon production is typically considered an undesired response as a result of the partition of photosynthetic resources to asexual reproduction of runners instead of fruit. Although stolon removal can be costly, 30\% decreases in strawberry yields have been reported when runners are not removed (Hughes et al., 2017). Although stolons were not removed until the end of each experiment, evaluating differences between cultivar runner production in facilities using CEA techniques could help to alleviate some of the manual labor costs without directly impacting strawberry fruit yields. 'Albion' is known for producing large numbers of stolons during outdoor and indoor cultivation, whereas high stolon production is typically not found with 'San Andreas' (University of California at Davis, n.d.). In our study, 'San Andreas' plants produced the least stolon weight whereas 'Albion' plants showed greater amounts of runner production throughout Expt. 1. During the lengthening days of Expt. 2 , both cultivars appeared to be more responsive to the SL provided by the LB and HB LED treatments, and both cultivars exhibited increased stolon production. Wu et al. (2011) also reported an increase in stolon production with plants grown under SS $70 \%$ red LED light and $30 \%$ blue LED light in a growth chamber.

\section{Conclusions}

LED SL caused a range of responses for the two cultivars of strawberries grown in a greenhouse at two different times of the year. The most responsive scenario across the two experiments was seen in the cultivar San Andreas during the shortening days in fall (Expt. 1), and using SL of either LB or HB. In that scenario, we observed improvement in overall berry quality (i.e., individual fruit weight, SSC, and overall yield) as well as vegetative growth (leaf area and crown number). Future studies should investigate optimum LED DLI on fruit production and yield of strawberry crops. SL is a key tool currently being used by CEA growers and researchers alike, and it shows potential in increasing offseason high-value crop production. Our results indicate that the addition of SL in the form of greater intensities of blue to red wavelengths, during shortening days, improves overall strawberry fruit quality and plant growth.

\section{Literature Cited}

Bradford, E., J. Hancock, and R. Warner. 2010. Interactions of temperature and photoperiod determine expression of repeat flowering in strawberry. J. Amer. Soc. Hort. Sci. 135:102107. 
Cherney, M. 2018. Aug. 16. Strawberry jam: Urbanfarming startups tackle a problem crop The Wall Street Journal, Dow Jones \& Company. 28 Aug. 2018. <www.wsj.com/articles/strawberry-jamurban-farming-startups-tackle-a-problem-crop$1534424400>$.

Choi, H., Moon, B., and Kang, N. 2015. Effects of LED light on the production of strawberry during cultivation in a plastic greenhouse and in a growth chamber. Scientia Hort. 189(25):22-31.

Conner, D.S., A.D. Montri, D.N. Montri, and M.W Hamm. 2009. Consumer demand for local produce at extended season farmers markets: Guiding farmer marketing strategies. Renew. Agr. Food Syst. 24(04):251-259.

Dorais, M. 2003. The use of supplemental lighting on vegetable crop production: Light intensity, crop response, nutrition, crop management, cultural practices. In: Canadian Greenhouse Conference. Agriculture and Agri-Food Canada, Laval University, QC.

Hamano, M., H. Yamazaki, T. Yano, M. Honjo, M. Morishita, and T. Maeda. 2016. Effect of photoperiod on flowering in everbearing strawberry 'Natsuakari'. Acta Hort. 1117:355-358.

Hanenberg, M., J. Janse, and W. Verkerke. 2016. LED light to improve strawberry flavour, quality and production. Acta Hort. 1137:207212.

Hemming, S. 2011. Use of natural and artificial light in horticulture: Interaction of plant and technology. Acta Hort. 907:25-35.

Hughes, B., J. Zandstra, T. Taghavi, and A. Dale. 2017. Effects of runner removal on productivity and plant growth of two day-neutral straw- berry cultivars in Ontario, Canada. Acta Hort. 1156:327-332.

Kimura, M. 2008. Vegetative growth and reproductive growth, p. 73-96. In: Encyclopedia in vegetable crops horticulture: Strawberry. 2nd ed. Nobunkyo, Tokyo, Japan.

Liu, X., T. Chang, S. Guo, Z. Xu, and J. Li. 2011. Effect of different light quality of LED ongrowth and photosynthetic character in cherry tomato seedling. Acta Hort. 907:325-330.

Magar, Y.G., K. Ohyama, A. Noguchi, W. Amaki, and S. Furufuji. 2018. Effects of light quality during supplemental lighting on the flowering in an everbearing strawberry. Acta Hort. 1206:279 284.

Massa, G.D., H.H. Kim, and R.M. Wheeler. 2008. Plant productivity in response to LED lighting. HortScience 43:1951-1956.

Morrow, R.C. 2008. LED lighting in horticulture. HortScience 43:1947-1950.

Nadalini, S., P. Zucchi, and C. Andreotti. 2017. Effects of blue and red LED lights on soilless cultivated strawberry growth performances and fruit quality. Eur. J. Hort. Sci. 82(1):12-20.

National Agricultural Statistics Service. 2017. Noncitrus fruits and nuts 2016 summary. 9 Apr. 2018. $<$ http://usda.mannlib.cornell.edu/MannUsda/ viewDocumentInfo.do?documentID $=1113>$.

National Weather Service. 2019. Sunrise and sunset information, Fort Collins, CO. 25 June 2019. $<$ https://www.weather.gov/mrx/sr_ss $>$.

Nishiyama, M. and K. Kanahama. 2000. Effect of temperature and photoperiod on the development of inflorescences in everbearing strawberry (Fragaria $\times$ ananassa Duch.) plants. Acta Hort. 514:261-267.
Park, Y.H., H.Y. Ryu, H.M. Choo, M.H. Kim, and B.S. Seo. 2014. Effect of different supplement lights for strawberry growth and fruit quality. Acta Hort. 1049:903-906.

Samuolienè, G., A. Brazaityte, A. Urbonaviciute, G. Šabajeviene, and P. Duchovskis. 2010. The effect of red and blue light component on the growth and development of frigo strawberries Zemdirbyte - Agr. 97(2):99-104.

Singh, D., C. Basu, M. Meinhardt-Wollweber, and B. Roth. 2015. LEDs for energy efficient greenhouse lighting. Renew. Sustain. Energy Rev. 49:139-147.

Son, K., E. Kim, and M. Oh. 2018. Growth and development of cherry tomato seedlings grown under various combined ratios of red to blue LED lights and fruit yield and quality after transplanting. Protected Horticulture and Plant Factory 27:54-63.

University of California at Davis. n.d. The UC patented strawberry cultivars, Office of Research. 8 May 2017. <https://research.ucdavis.edu/industry/ia/industry/strawberry/cultivars/ $>$.

U.S. Department of Agriculture. 2006. Strawberries grades and standards. 8 May 2017. $<$ https://www.ams.usda.gov/grades-standards/ strawberries-grades-and-standards $>$.

Wu, C., S. Hsu, M. Chang, and W. Fang. 2011. Effect of light environment on runner plant propagation of strawberry. Acta Hort. 907:297-302.

Yoshida, H., D. Mizuta, N. Fukuda, S. Hikosaka, and E. Goto. 2016. Effects of varying light quality from single-peak blue and red light-emitting diodes during nursery period on flowering, photosynthesis, growth, and fruit yield of everbearing strawberry. Plant Biotechnol. 33(4):267-276. 